$\underline{\text { Review Article }}$

\title{
RECENT ADVANCES INPHARMACOTHERAPY OF ALZHEIMER'S DISEASE
}

\author{
ARVIND NARWAT ${ }^{1}$, VIVEK SHARMA ${ }^{2}$, SUNEEL KUMAR ${ }^{3 *}$, SEEMA RANI ${ }^{4}$ \\ ${ }^{1}$ Demonstrator, Department of Pharmacology, B. P. S. Government Medical College For Women, Khanpur Kalan, Sonipat Haryana, \\ ${ }^{2}$ Department of Pharmacology, Pandit Bhagwat Dayal Sharma Post Graduate Institute of Medical Sciences, Rohtak, Haryana, ${ }^{3}$ Department \\ of Pharmacology, Pandit Bhagwat Dayal Sharma Post Graduate Institute of Medical Sciences, Rohtak, Haryana, ${ }^{4}$ Department of \\ Pharmacology, B. P. S. Government Medical College For Women, Khanpur Kalan, Sonipat Haryana \\ Email: drsuneelrohilla@gmail.com \\ Received: 06 Aug 2021, Revised and Accepted: 10 Oct 2021
}

\section{ABSTRACT}

The management of Alzheimer's disease (AD) has been a long-standing challenge and area of interest. Advances in knowledge of the pathogenesis of disease and an increase in disease burden have prompted investigation into innovative therapeutics over the last two decades. Current approved therapies are symptomatic treatments having some effect on cognitive function. Therapies that target $\beta$-amyloid (A $\beta$ ) have been the focus of efforts to develop a disease modification treatment for AD but these approaches have failed to show any clinical benefit so far. Beyond the 'A $\beta$ hypothesis', there are a number of newer approaches to treat AD. This short review will summarize approved drug therapies, recent clinical trials and new approaches for the treatment of $\mathrm{AD}$.

Keywords: Alzheimer's disease (AD), $\beta$-amyloid (Aß), Tau proteins, Recent advance

(C) 2021 The Authors. Published by Innovare Academic Sciences Pvt Ltd. This is an open access article under the CC BY license (https://creativecommons.org/licenses/by/4.0/) DOI: https://dx.doi.org/10.22159/ijcpr.2021v13i6.1916 Journal homepage: https://innovareacademics.in/journals/index.php/ijcpr

\section{INTRODUCTION}

Alzheimer's disease (AD) is a critical neurodegenerative illness characterized by the gradual development of forgetfulness, progressing to disturbances in language, dyscalculia/acalculia, visuospatial disorientation, ideational and ideomotor apraxia, akinesia, and mutism. ${ }^{1}$ Epidemiological data show that the occurrence of $\mathrm{AD}$ increases with age and doubles every $5 \mathrm{y}$ after $65 \mathrm{y}$ of age.[2-3]There were about 26.6 million cases of AD in the world in 2006 and it is predictable that the worldwide dominance of AD will grow fourfold to 106.8 million by the year $2050 .{ }^{4}$ Classical pathological hallmarks are senile plaques, comprised principally of amyloid-b (Ab), and neurofibrillary tangles which consist of phosphorylated tau as shown in fig. 1 and 2.
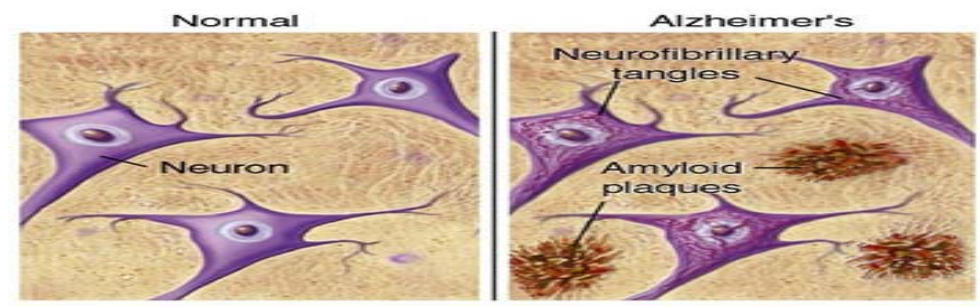

Fig. 1: Microtubules transport nutrition and other molecules

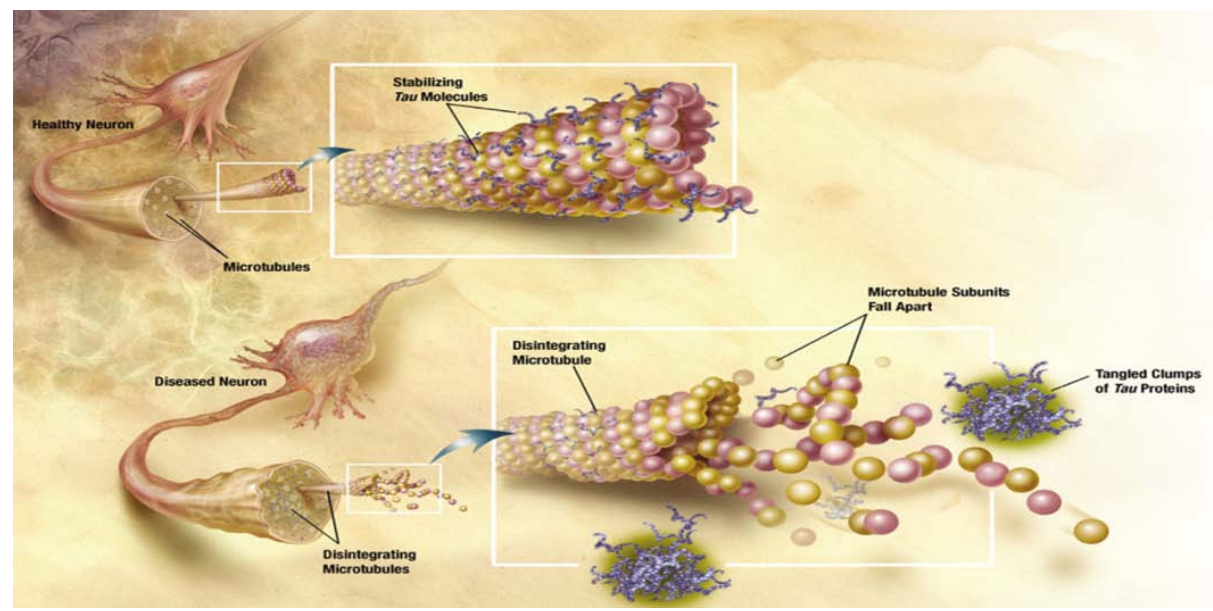

Fig. 2: Microtubules transport nutrition and other molecules. Tau-proteins act as "ties" that stabilize the structure of the microtubules. In $\mathrm{AD}$, tau proteins become tangled, un-stabilizing the structure of the microtubule 
These two hallmark lesions are the basis for standard neuropathological criteria for $\mathrm{AD}$, including the Consortium to Establish a Registry for Alzheimer's disease (CERAD), National Institute on Aging-Reagan, and Braak criteria. [5-6]The proposed pathogenic mechanisms for $\mathrm{AD}$ generally comprise the basis for current attempts at therapeutic intervention. These include loss of cholinergic function (cholinergicreplacement therapy and neurotropins), oxidative stress (antioxidant therapy), the amyloid cascade (Ab vaccine, bandg-secretase effectors, statins), inflammatory mediators (NSAIDs), steroid hormone deficiencies (hormone replacement therapy), excitotoxicity (memantine), and the role of dietary factors (low saturated fat diets, moderate alcohol intake) as shown in table 1.

Table 1: Showing current treatment of Alzheimer disease based on pathogenic mechanism

\begin{tabular}{ll}
\hline Pathogenic mechanism & Treatment \\
\hline Cholinergic deficiency & Cholinesterase inhibitors: \\
& $1^{\text {st }}$ generation: Tacrine \\
Oxidative stress & Alpha-tocopherol, Selegeline \\
Amyloid cascade & Statins, Secretase effectors \\
Inflammation & NSAIDs \\
Excitotoxicity & Memantine \\
Other & Mediterranean diet \\
\hline
\end{tabular}

\section{Why is there need for new drug?? Because current treayment}

- Do not address underlying pathology of $\mathrm{AD}$

- Positive benefits are relatively short term

- No treatment to reverse, stop or slow neurodegenerative process

- None of the drugs have disease modifying effects that can halt the progression of disease and stop cognitive decline

New targets and compounds for treatment of Alzheimer disease are shown in table 2:

\section{Anti-amyloid therapy}

Anti-amyloid therapy involves the uses of drugs (see in table 2) with a different mechanism of actions: (i) enhance the clearance of $A \beta$; (ii) Prevent the production of $A \beta$; or (iii) Inhibit the accumulation of $A \beta$ [11]. Active and passive immunization results in decreased levels of intracerebral $A \beta$ burden by inducing humoral reaction against the $A \beta$ peptide leading to its clearance from the brain [12].

\section{$\boldsymbol{\gamma}$-Secretase inhibitors (GSI) and modulators (GSM)}

$\gamma$-secretase is a trans membrane protease responsible for cleavage of amyloid precursor protein (APP) to produce A $\beta$. Different GSIs such as DAPT, L685458 andMRK-560 131 have been recently developed [13]. While different (GSM) such as avagacestat (BMS-708163), begacestat and NIC5-15 are under clinical trials.

\section{Therapy for mitochondrial dysfunction}

Latrepirdine (DIMEBON), an antihistamine which preserves mitochondrial structure and function and protects against A[?] induced apoptosis is under investigation. Its combination with donepezil is also under investigation. AC-1204 is considered to improve mitochondrial metabolism by inducing chronic ketosis, thereby releasing regional cerebral hypometabolism presented in early Alzheimer's disease, and this agent is also under investigation [14].

Table 2: Showing new targets and compounds [7-10]

\begin{tabular}{lll}
\hline Compound & Target/Treatment & Current phase \\
\hline ANI-1792 & Vaccine-active immunization & Interrupted at phase I (severe side effects such as meningoencephalitis) \\
CAD-106 & Vaccine-active immunization & Phase I (ongoing) \\
Bapineuzumab & Beta-amyloid monoclonal antibody & Phase III (ongoing) \\
Solanezumab & Beta-amyloid monoclonal antibody & Phase III (ongoing) \\
Ponezumab & Beta-amyloid monoclonal antibody & Interrupted at phase II (no efficacy) \\
Gantenerzumab & Beta-amyloid monoclonal antibody & Phase I (ongoing) \\
Crenezumab & Beta-amyloid monoclonal antibody & Phase I (ongoing) \\
Semagacestat & Gamma-secretase inhibitor & Interrupted at phase III (no efficacy and risk for skin cancer) \\
Avagacestat & Gamma-secretase inhibitor & Phase II (ongoing) \\
GRL-834 & Beta-secretase inhibitor & Ongoing \\
TAK-070 & Beta-secretase inhibitor & Ongoing \\
CHF-5074 & Non-steroid anti-inflammatory agent & Ongoing \\
DAPT & Prototypal Gamma-secretase inhibitor & Ongoing \\
Curcumin & Anti-amyloid aggregator & Ongoing
\end{tabular}

\section{Kinase inhibitors}

The first class of tau inhibitors which helps in targeting tau phosphorylation and reduces tau phosphorylation by decreasing the activity of kinase enzyme. Interaction between glycogen synthase kinase 3 beta (GSK3 $\beta \beta$ ) and protein phosphate 2 (PP2A) augments tau hyper phosphorylation and NFT generation. Lithium, valproate, NP031112 (NP-12) and epothilone D (BMS-241027) decreases tau phosphorylation and prevent reversed features of tauopathy $[15,16]$.

\section{$\beta \beta$-Secretase (BACE1) inhibitor}

Beta-site APP-cleaving enzyme 1 (BACE1) is a protease responsible for cleavage of APP, resulting in generation of assembly of neurotoxic irregular $\mathrm{A} \beta \beta$. Nuclear peroxisome proliferator activated receptor gamma (PPAR $\gamma \gamma$ ) functions as a transcription factor which regulates gene expression promotes microglia-mediated $\mathrm{A} \beta \beta$ endocytosis. Also it reduces inflammation response and causes decreased cytokine excretion. Thiazolidinedione can induce PPAR $\gamma \gamma$ to inhibit $\beta \beta$-secretase and stimulate ubiquitination to worsen amyloid burden. It has been also reported that PPAR $\gamma \gamma$ agonist i.e. thiazolidinedione derivatives like rosiglitazone and pioglitazone worsens $\mathrm{AD}$ neuropathology by reducing insulin sensitivity which helps in $\mathrm{A} \beta \beta$ proteolysis [17].

\section{Anticholinergic therapy}

Anticholinergic therapy includes administration of cholinesterase inhibitors to treat the cholinergic deficit associated with AD. The 
drugs include tacrine (COGNEXS), donepezil (ARICEPTS), rivastigmine (EXELON), and galantamine (REMINYLS) [18].

\section{Immunotherapy}

In the attempt to avoid adverse $\mathrm{T}$ cell mediated immune response, many vaccination modalities under current investigation are directed towards the humoral response. Nasal immunization of an $\mathrm{AD}$ mouse model with AdPEDI-(Ab1e 6) demonstrated a predominantly IgG1 response and reduced $\mathrm{Ab}$ load in the brain. Transcutaneous immunization has also been studied in mice with aggregated Ab1e42 plus the adjuvant cholera toxin. This animal study showed significant decreases in cerebral Ab1e40, 42 levels in the setting of increased circulating levels of Ab1e 40,42 without the side effects of brain $\mathrm{T}$ cell infiltration or microhemorrhage [19].

\section{Clioquinol}

Metal chelation using clioquinol has been reported in apilot study with 36 patients with $\mathrm{AD}$ to reduce the rate ofcognitive loss in a double-blind, placebo-controlled, phase 2 clinical trial Clioquinol's effect in this preliminarystudy is due to its ability to chelate zinc and copperassociated with amyloid plaques. The mobilization andremoval of brain amyloid is believed to be basis of itstherapeutic effect. It was reported that clioquinol canreduce zinc accumulation in neuritic plaques and inhibitthe amyloidogenic pathway in APP/PS1 transgenic mouse brain [20].

\section{Resveratrol}

Resveratrol, a red wine polyphenol, is known to protect against cardiovascular diseases and cancers, as well as to promote anti-aging effects in numerous organisms. Some recent studies on red wine bioactive compounds suggest that resveratrol modulates multiple mechanisms of $\mathrm{AD}$ pathology. It has been recently suggested that resveratrol can be effective in slowing down $A D$ development. As reported in many biochemical studies, resveratrol seems to exert its neuroprotective role through inhibition of $A \beta$ aggregation, by scavenging oxidants and exerting anti-inflammatory activities [21].

\section{Nicotine}

Nicotine is a cholinergic agonist that acts both postsynaptically and pre-synaptically to release acetylcholine,which is an alkaloid derived from the leaves of tobacco plants (Nicotianatabacum and Nicotianarustica). Nicotinic receptor densities are further attenuated in age associated neurodegenerative disorders in the elderly, such as AD. Numerous investigations, both in vivo and in vitro, indicate that nicotine can enhance neurone survival in response to a range of neurotoxic insults [22]

\section{CONCLUSION}

The pathogenesis of $\mathrm{AD}$ is a complex process involving both genetic and environmental factors; therefore development of effective diseasemodifying drugs is proving to be a difficult task. Herein, we have made an effort to review recent trends in $\mathrm{AD}$. The Current therapies for patients with $\mathrm{AD}$ may ease symptoms by providing temporary improvement and reducing the rate of cognitive decline. It is hoped that all these lines of ongoing research, should lead to a deeper understanding of the progressions that happen in the brain of Alzheimer patient to permit us to preclude efficiently their incidence. Thus, we conclude that these categories of drugs discussed in this review can be potentially targeted for research and development for the treatment of AD.

\section{ACKNOWLEDGEMENT}

Dr. Vivek Sharma, Dr. Suneel

\section{FUNDING}

None

\section{AUTHORS CONTRIBUTIONS}

All the authors have contributed equally.

\section{CONFLICT OF INTERESTS}

Declared none

\section{REFERENCES}

1. Selkoe DJ. Alzheimer's disease: genes, proteins, and therapy. Physiol Rev. 2001;81(2):741-66. doi: 10.1152/physrev. 2001.81.2.741, PMID 11274343.

2. Querfurth HW, LaFerla FM. Alzheimer's disease. N Engl J Med. 2010;362(4):329-44. doi: 10.1056/NEJMra0909142, PMID 20107219.

3. Mayeux R. Clinical practice. Early Alzheimer's disease. N Engl J Med. 2010;362(23):2194-201. doi: 10.1056/NEJMcp0910236, PMID 20558370.

4. Brookmeyer R, Johnson E, Ziegler Graham K, Arrighi HM. Forecasting the global burden of Alzheimer's disease. Alzheimers Dement. 2007;3(3):186-91. doi: 10.1016/j.jalz.2007.04.381, PMID 19595937.

5. Braak H, Braak E. Neuropathologicalstageing of alzheimerrelatedchanges. Acta Neuropathol. 1991;82(4):239-59. doi: 10.1007/BF00308809.

6. Hyman BT, Trojanowski JQ. Editorial on consensus recommendations for the postmortem diagnosis of Alzheimer disease from the National Institute on Aging and the Reagan Institute Working Group on diagnostic criteria for the neuropathological assessment of Alzheimer disease. I Neuropathol Exp Neurol. 1997;56(10):1095-7. doi: 10.1097/00005072-199710000-00002.

7. Aprahamian I, Stella F, Forlenza OV. New treatment strategies for Alzheimer's disease: is there a hope? Indian J Med Res. 2013;138(4):449-60. PMID 24434253.

8. Bolognesi ML, Bartolini M, Tarozzi A, Morroni F, Lizzi F, Milelli A, Minarini A, Rosini M, Hrelia P, Andrisano V, Melchiorre C. Multitargeted drugs discovery: balancing anti-amyloid and anticholinesterase capacity in a single chemical entity. Bioorg Med Chem Lett. 2011;21(9):2655-8. doi: 10.1016/ j.bmcl.2010.12.093, PMID 21236667.

9. Nagaraja Prasad S, Jagadeesh K, Vedavathi H, Shreenivas P. Alzheimer disease: therapeutic targets and recent developments in treatment. SchAcad J Pharm. 2015;4:222-5.

10. Wiessner C, Wiederhold KH, Tissot AC, Frey P, Danner S, Jacobson LH, Jennings GT, Luond R, Ortmann R, Reichwald J, Zurini M, Mir A, Bachmann MF, Staufenbiel M. The secondgeneration active $A \beta$ immunotherapy CAD106 reduces amyloid accumulation in APP transgenic mice while minimizing potential side effects. J Neurosci. 2011;31(25):9323-31. doi: 10.1523/JNEUROSCI.0293-11.2011, PMID 21697382.

11. Salomone S, Caraci F, Leggio GM, Fedotova J, Drago F. New pharmacological strategies for treatment of Alzheimer's disease: focus on disease modifying drugs. Br J Clin Pharmacol. 2012;73(4):504-17. doi: 10.1111/j.1365-2125.2011.04134.x, PMID 22035455

12. Panza F, Frisardi V, Imbimbo BP, Seripa D, Paris F, Santamato A. Anti- $\beta$-amyloid immunotherapy for Alzheimer's disease: focus. Colomb Med (Cali). 2016;47(4):203-12. PMID: 28293044.

13. Zhao B, Yu M, Neitzel M, Marugg J, Jagodzinski J, Lee M, Hu K, Schenk D, Yednock T, Basi G. Identification of $\gamma$-secretase inhibitor potency determinants on presenilin. J Biol Chem. 2008;283(5):2927-38. doi: 10.1074/jbc.M708870200, PMID 18032377.

14. Tariot P, Sabbagh M, Flitman S, Reyes P, Taber L, Seely L. P1254: A safety, tolerability and pharmacokinetic study of dimebon in patients with Alzheimer's disease already receiving donepezil. Alzheimers Dem. 2009;5(4S_Part_8):251. doi: 10.1016/j.jalz.2009.04.262.

15. Jia Q, Deng Y, Qing H. Potential therapeutic strategies for Alzheimer's disease targeting or beyond $\beta$-amyloid: insights from clinical trials. Biomed Res Int. 2014;2014:837157. doi: 10.1155/2014/837157. PMID 25136630.

16. Sereno L, Coma M, Rodriguez M, Sanchez-Ferrer P, Sanchez MB, Gich I, Agullo JM, Perez M, Avila J, Guardia Laguarta C, Clarimon J, Lleo A, Gomez-Isla T. A novel GSK-3beta inhibitor reduces Alzheimer's pathology and rescues neuronal loss in vivo. Neurobiol Dis. 2009;35(3):359-67. doi: 10.1016/ j.nbd.2009.05.025, PMID 19523516.

17. Craft S. The role of metabolic disorders in Alzheimer disease and vascular dementia: two roads converged. Arch Neurol. 
2009:66(3):300-5. doi: 10.1001/archneurol.2009.27, PMID 19273747.

18. Nordberg A, Darreh-Shori T, Svenson A, Guan Z. AChE and BuChE activities in CSF of mild AD patients following 12 mo of rivastigmine treatment. J Neurol Sci. 2001:187:0144.

19. Nikolic WV, Bai Y, Obregon D, Hou H, Mori T, Zeng J, Ehrhart J, Shytle RD, Giunta B, Morgan D, Town T, Tan J. Transcutaneous beta-amyloid immunization reduces cerebral beta-amyloid deposits without $\mathrm{T}$ cell infiltration and microhemorrhage. Proc Natl Acad Sci USA. 2007;104(7):2507-12. doi: 10.1073/ pnas.0609377104, PMID 17264212.

20. Wang T, Wang CY, Shan ZY, Teng WP, Wang ZY. Clioquinol reduces zinc accumulation in neuritic plaques and inhibits the amyloidogenic pathway in A $\beta$ PP/PS1 transgenic mouse brain. J Alzheimers Dis. 2012;29(3):549-59. doi: 10.3233/JAD-2011111874, PMID 22269164.

21. Huang TC, Lu KT, Wo YY, Wu YJ, Yang YL. Resveratrol protects rats from $A \beta$-induced neurotoxicity by the reduction of iNOS expression and lipid peroxidation. Plos One. 2011;6(12):e29102. doi: 10.1371/journal.pone.0029102, PMID 22220203.

22. Graham AJ, Martin Ruiz CM, Teaktong T, Ray MA, Court JA. Human brain nicotinic receptors, their distribution and participation in neuropsychiatric disorders. Curr Drug Targets CNS Neurol Disord. 2002;1(4):387-97. doi: 10.2174/ 1568007023339283 , PMID 12769611. 